\title{
Population structure of albacore (Thunnus alalunga) in the Northwestern Pacific Ocean inferred from mitochondrial DNA
}

\author{
Georgiana Cho-Chen $\mathrm{Wu}^{\mathrm{a}, 1}$, Hsin-Chieh Chiang ${ }^{\mathrm{b}, 1}$, Kuo-Shu Chen ${ }^{\mathrm{b}}$, \\ Chien-Chung Hsu ${ }^{\mathrm{b}, *}$, Hsi-Yuan Yang ${ }^{\mathrm{a}, *}$ \\ a Institute of Molecular and Cellular Biology, National Taiwan University, Taipei, Taiwan, ROC \\ ${ }^{\mathrm{b}}$ Institute of Oceanography, National Taiwan University, Taipei, Taiwan, ROC
}

\section{A R T I C L E I N F O}

\section{Article history:}

Received 10 January 2008

Received in revised form 23 July 2008

Accepted 27 July 2008

\section{Keywords:}

Albacore (Thunnus alalunga)

Mitochondrial DNA

Control region

Population structure

Northwestern Pacific Ocean

\begin{abstract}
A B S T R A C T
Albacore (Thunnus alalunga) is a highly migratory cosmopolitan fish commonly distributed throughout all oceans. It is an important commercial species in the world fisheries. In the present study, population structure of albacore in the Northwestern Pacific Ocean was investigated using mitochondrial DNA sequence data analysis. A total of 175 individuals were sampled from three regions in the Northwestern Pacific Ocean (Taiwan, Japan and North of Hawaii) and among them, 168 haplotypes were revealed. Nucleotide diversities and haplotypic diversities were high in all sampling regions. The reconstructed neighbor-joining tree based on the Kimura two-parameter model indicated that two clades of albacore coexisted in the Northwestern Pacific Ocean. Clade I is the main clade consisting of $98 \%$ of the total specimens and is further divided into two lineages (Lineages I and II). Hierarchical AMOVA tests and pairwise $\Phi_{\text {ST }}$ analysis showed that albacore tuna in the Northwestern Pacific Ocean constituted a single stock with no significant differences in geographic distributions.
\end{abstract}

(c) 2008 Published by Elsevier B.V.

\section{Introduction}

Albacore (Thunnus alalunga), also known as longfin tuna, is recognized by its remarkably long and slender pectoral fins about 30\% of its fork length. It is a highly migratory pelagic fish inhabiting waters at $13.5-25.2^{\circ} \mathrm{C}$ of all oceans including the Mediterranean but not the Gulf of Mexico (Collette and Nauen, 1983). Albacore has a high commercial value in world fisheries. In recent years, increasing concerns on the albacore stock status due to worldwide overfishing has been pointed out (Bard, 2001; Uozumi, 2004). Thus, a better understanding of its genetic structure would definitely aid to a more effective fishery management strategy.

In 1995, Chow and Ushiama detected highly significant heterogeneity between the Pacific and Atlantic albacore but no heterogeneity within each ocean using restriction fragment length polymorphism (RFLP) analysis of the mitochondrial ATPase gene. However, later studies using the same sample lots inferred from microsatellite DNA analysis suggested much higher genetic structuring between the North and South stocks of each ocean (Takagi et al., 2001 ). Furthermore, blood groups and tag-recapture analyses

\footnotetext{
* Corresponding authors. Tel.: +886 2 33662479; fax: +8862 33662478

E-mail address: hyhy@ntu.edu.tw (H.-Y. Yang).

1 These authors contributed equally to this work.
}

(Arrizabalaga et al., 2004) suggested no gene flow between these two oceans.

Regarding the Atlantic Ocean and the Mediterranean Sea, mitochondrial DNA (mtDNA) sequence analysis performed by Viñas et al. (1999) and allozyme analysis conducted by Pujolar et al. (2003) had detected no genetic differentiation between the two populations. In contrast, genetic differentiation between the North Atlantic and Mediterranean albacores was detected by blood groups and tag-recapture analyses (Arrizabalaga et al., 2004), mtDNA control region sequencing methods (Viñas et al., 2004; Nakadate et al., 2005), and nuclear glucose-6-phosphate dehydrogenase (G6PD) DNA RFLP analysis (Nakadate et al., 2005). Lastly, regarding the Indian Ocean, both morphometric and mtDNA sequencing analyses suggested the Indian Ocean albacore samples to be divided by the $90^{\circ}$ E longitude into two major groups (Yeh et al., 1996) In 2004, blood-group analysis also suggested that the Indian albacore population is similar to those of the South Atlantic Ocean (Arrizabalaga et al., 2004).

The inconsistency of the above data may be due to different analysis methods used. Furthermore, albacore genetic structure of the Northwestern Pacific Ocean remains unexplored despite the fact that this area is also an important fishing ground. Prior to the present study, only one molecular sequencing investigation was performed on the Pacific albacore (Viñas et al., 2004). Over the years, mtDNA sequencing was shown to be one of the more 
effective approaches in predicting population structures among numeral other molecular techniques (Buonnacorsi et al., 2001). In this study, 175 albacore samples were collected from 3 different regions namely Taiwan, Japan and North of Hawaii of the Northwestern Pacific Ocean. Amplification and sequencing of the mtDNA control region were completed, and subsequent analyses were carried out specifically targeting its first hyper-variable region (HVR-1) to access stock structure and phylogenetic information of albacores in these waters.

\section{Materials and methods}

\subsection{Sampling and DNA sequencing}

Albacore samples were collected by commercial fishing vessels from three local regions of the Northwestern Pacific Ocean during January 2002 to July 2004: Taiwan $(n=95)$, Japan $(n=50)$ and North of Hawaii $(n=30)$ (Fig. 1 and Table 1 ). Samples of muscle tissue were preserved in $95 \%$ ethanol and stored frozen at $-20^{\circ} \mathrm{C}$ until DNA extraction.

DNA extraction, amplification and sequencing were performed as previously described (Chiang et al., 2006, 2008). The two primers used in this procedure were: the forward primer, TAF (5'-TAC CCC AAA CTC CCA AAG CTA-3') located inside the proline tRNA gene which flanks the $5^{\prime}$ end of the control region and the reverse primer, TAR (5'-GCG GAG GCT TGC ATG TGT A -3') located inside the phenylalanine tRNA gene which flanks the $3^{\prime}$ end of the control region. Amplification conditions are listed as followed: initial denaturation at $94^{\circ} \mathrm{C}$ for $5 \mathrm{~min}$, followed by 30 amplification cycles (denaturation at $94{ }^{\circ} \mathrm{C}$ for $45 \mathrm{~s}$, annealing at $53^{\circ} \mathrm{C}$ for $45 \mathrm{~s}$ and extension at $72{ }^{\circ} \mathrm{C}$ for $1 \mathrm{~min}$ ) with a final extension at $72^{\circ} \mathrm{C}$ for $5 \mathrm{~min}$. The sequencing primers used were the PCR primers, TAF and TAR.

\subsection{Data analyses}

In addition to haplotypes derived from this study, several orthologous mtDNA sequences of other species were added to the gene pool as out-groups for analysis. These included: two bluefin tuna (Thunnus thynnus) of Accession Nos. AF390438 and AF390439 (renamed to be NBF02 and NBF01, respectively) and three yellowfin tuna (Thunnus albacares) of Accession Nos. AF301203, AF301206 and AF301207 from GenBank (http://www.ncbi.nlm.nih.gov/), along with four previously published bigeye tuna (Thunnus obesus) mtDNA control region sequences from Chiang et al. (2006).
DNA sequences were aligned by ClustalX, version 1.83 (Thompson et al., 1997), then subsequently optimized by eye (e.g., gap-filling, nucleotide editing) in BIOEDIT, version 7.0.5.3 (Hall, 1999).

The phylogenetic trees were constructed by the Neighborjoining (NJ) method (Saitou and Nei, 1987) using the Kimura-twoparameter (K2P) model (Kimura, 1980) in MEGA, version 3.1 (Kumar et al., 2004). The statistical robustness in the nodes of the resulting tree was determined by 1000 bootstrap replicates (Felsenstein, 1985).

Arlequin, version 2.000 (Schneider et al., 2000), DnaSP, version 4.0 (Rozas et al., 2003) and MEGA, version 3.1 (Kumar et al., 2004) were used to calculate statistical values such as the nucleotide composition, number of polymorphic sites $(S)$, haplotype diversity $(H \mathrm{~d}$; Nei, 1987), nucleotide diversity ( $\pi$; Lynch and Crease, 1990), average number of pairwise nucleotide differences ( $k$; Tajima, 1983) and the expected heterozygosity per site $(\theta$; Watterson, 1975) were calculated for each geographic population. The isolation-by-distance effects on population genetic structure were estimated by pairwise $F_{\mathrm{ST}}$ statistics (Wright, 1951, 1965), for which computations of the correlation between pairwise geographic and genetic distances between populations were statistically analyzed by means of the Mantel test (Mantel, 1967; Smouse et al., 1986). The amounts of genetic variability partitioned within and among populations were accessed by an analysis of molecular variance (AMOVA; Excoffier et al., 1992). Significance of pairwise population comparison was tested by 20,000 permutations. Organization of the AMOVA tests was in a hierarchical manner and 1000 permutation procedures were used to construct null distributions and to test the significance of variance components (Guo and Thompson, 1992).

The entire mitochondrial control region data set revealed from the phylogenetic analysis was tested against constant population size and sudden population expansion models using the mismatch distribution as implemented in Arlequin, version 2.000 (Schneider et al., 2000) and DnaSP 4.0 (Rozas et al., 2003). The fit between the observed and expected distributions was tested using the Harpending raggedness index (Hri; Harpending, 1994) and sum of squared deviations (SSD) for the estimated stepwise expansion models (Schneider and Excoffier, 1999).

Tajima's D (Tajima, 1989a,b) and Fu's Fs (Fu, 1997) tests conducted through Arlequin, version 2.000 (Schneider et al., 2000) were carried out to examine for deviations from neutrality (as would be expected under population expansion). Tajima's test is

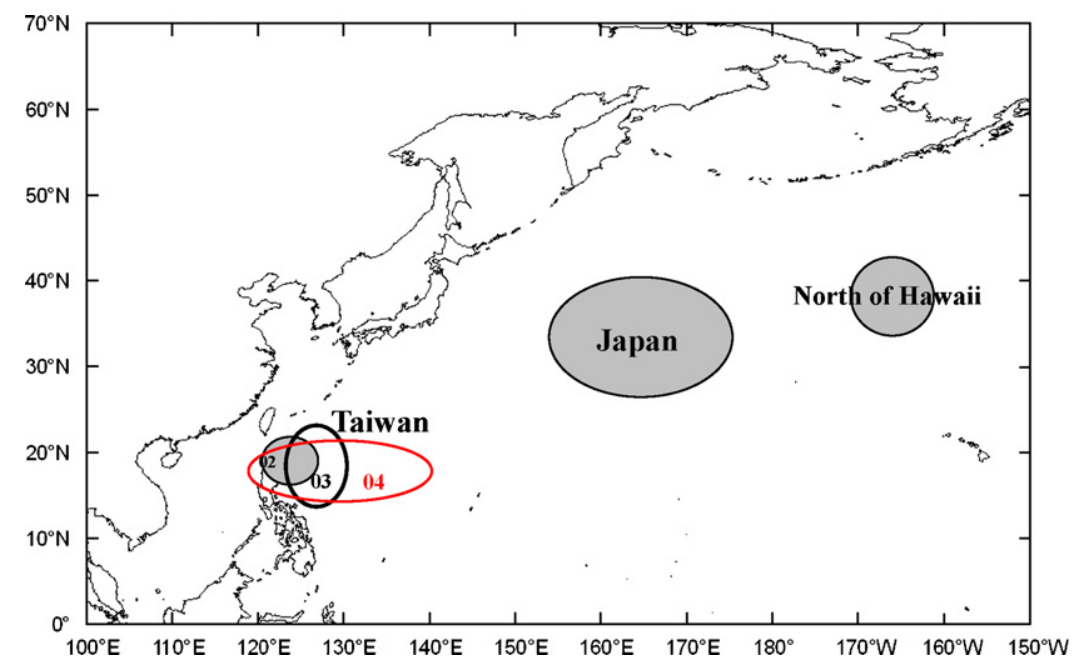

Fig. 1. Map showing the T. alalunga sampling areas under study. 
Table 1

Descriptive statistics for the studied T. alalunga samples

\begin{tabular}{|c|c|c|c|c|c|c|c|c|c|}
\hline Population & Location & Date & $n$ & $H$ & $S$ & $H d$ & $k$ & $\pi$ & $\theta$ \\
\hline Taiwan 2002 & $123^{\circ}-129^{\circ} \mathrm{E} ; 18^{\circ}-22^{\circ} \mathrm{N}$ & June 2002 & 30 & 29 & 87 & $0.998 \pm 0.009$ & $23.5 \pm 10.7$ & $0.069 \pm 0.035$ & $23.5 \pm 11.9$ \\
\hline Taiwan 2003 & $124^{\circ}-130^{\circ} \mathrm{E} ; 14^{\circ}-23^{\circ} \mathrm{N}$ & April 2003 & 38 & 38 & 84 & $1.000 \pm 0.006$ & $20.8 \pm 9.4$ & $0.061 \pm 0.031$ & $20.7 \pm 6.4$ \\
\hline Taiwan 2004 & $119^{\circ}-140^{\circ} \mathrm{E} ; 14^{\circ}-21^{\circ} \mathrm{N}$ & July 2004 & 27 & 26 & 76 & $0.997 \pm 0.011$ & $22.1 \pm 10.1$ & $0.065 \pm 0.033$ & $20.5 \pm 6.8$ \\
\hline Japan & $153^{\circ}-175^{\circ} \mathrm{E} ; 27^{\circ}-41^{\circ} \mathrm{N}$ & January 2002 & 50 & 47 & 92 & $0.997 \pm 0.005$ & $23.6 \pm 10.5$ & $0.069 \pm 0.034$ & $21.0 \pm 6.1$ \\
\hline Hawaii & $161^{\circ}-171^{\circ} \mathrm{W} ; 34^{\circ}-43^{\circ} \mathrm{N}$ & October 2002 & 30 & 28 & 68 & $0.991 \pm 0.012$ & $20.5 \pm 9.3$ & $0.060 \pm 0.030$ & $17.2 \pm 5.6$ \\
\hline
\end{tabular}

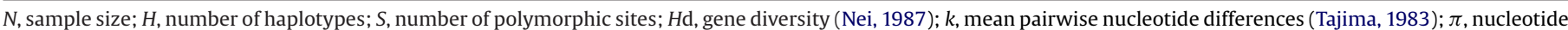
diversity (Nei, 1987); $\theta$, expected heterozygosity per site (Watterson, 1975).

widely used as a test for neutrality, and Fu's Fs test outperforms other tests in detecting population growth for large sample sizes (Ramos-Onsins and Rozas, 2002).

\section{Results}

\subsection{Molecular characteristics}

The entire mtDNA control region fragment approximately $860 \mathrm{bp}$ in length immediately flanking the $t R N A^{\text {Pro }}$ gene was sequenced in 175 albacores. Analyses of the current study aimed solely at the 366 bp HVR-1 region for sequence comparisons since this fragment is the most highly variable and informative among the whole D-loop segment. In total, 130 variable sites were observed and 168 haplotypes defined. A/T base contents were higher than C/G base contents among the sequences examined (mean: $A=36.5 \%$, $\mathrm{T}=29.7 \%, \mathrm{C}=20.2 \%$ and $\mathrm{G}=13.7 \%$ ), consistent with previous studies showing the D-loop to be an A-T rich region of the mitochondrial genome (Brown et al., 1986; Saccone et al., 1987). Among the 130 polymorphic sites observed, 33 were singleton variable sites and 97 were parsimony-informative. Both nucleotide diversities (average $\pi=0.065$ ) and haplotype diversities (average $h=0.998$ ) were high between samples. Regional population genetic statistics are listed in Table 1.

\subsection{Phylogeny and patterns of population structure}

The reconstructed Neighbor-joining phylogeny tree using the K2P model was presented in Fig. 2. Albacore haplotypes from all three sampling regions were grouped into two divergent clades, Clades I and II. Clade I contained most (98\%) of the specimens in each of the three sampling regions (Taiwan $=99 \%$, Japan $=94 \%$, North of Hawaii $=100 \%$ ) and was weakly supported by a bootstrap value of $52 \%$. Two lineages (Lineages I and II) were revealed among the haplotypes of Clade I. Lineage I was supported by a bootstrap value of $<50 \%$ and lineage II by a value of $54 \%$. On the other hand, Clade II, strongly supported by a bootstrap value of $99 \%$, contained a fairly small amount (2\%) of specimens, including none from North of Hawaii. Overall, there seemed to be no geographic structuring among haplotypes in Clade I and Clade II. However, one exception was observed in North of Hawaii where no Clade II was found.

Hierarchical AMOVA analysis was first performed using the K2P model for the Taiwan samples taken in three separate years (Table 1) and no structure was revealed (data not shown). Thus, these samples were grouped into one as the Taiwan sample in the present study. Further AMOVA analysis revealed no structure $\left(\Phi_{\mathrm{ST}}=-0.001 ; p=0.40\right)$ among the entire albacore collections. Moreover, no structure was revealed for either Lineage I $\left(\Phi_{\mathrm{ST}}=0.006 ; p=0.22\right)$ or II $\left(\Phi_{\mathrm{ST}}=-0.019 ; p=0.98\right)$ or for the whole Clade I population $\left(\Phi_{S T}=-0.00357 ; p=0.58\right)$. Pairwise $F_{S T}$ values ranging from -0.0125 to 0.004 with all the $p$-values over 0.05 showed no significant differentiation between any two of the three sampling regions.

\subsection{Demographic patterns}

The Harpending's raggedness index (Hri; Harpending, 1994), sum of squared deviations (SSD) and other demographic parameters of the expansion model for the entire HVR-1 data set and the phylogroups of albacores were listed in Table 2. Mismatch distribution analysis on the entire data set revealed a bimodal shape; one mode corresponded to the number of differences between the two lineages of Clade I, and the other to differences among individuals within both lineages. In addition, a unimodal distribution was revealed by each of the separate analysis of the two lineages (figure not shown). According to the measured sum of squared deviation (SSD; $p>0.05$ ), the observed data results were interpreted as of non-significant differences from that predicted by the growth expansion model. Furthermore, the low Harpending's raggedness index values suggested a significant fit between the observed and the expected distributions, which further supported population expansion. Derived from the diversity index $\theta=2 N_{\mathrm{f}} \mu$, where $N_{\mathrm{f}}$ is the effective female population size and $\mu$ is the mutation rate per sequence per generation, the estimated effective female population size after expansion $\left(\theta_{1}\right)$ was about 20 and 50 times higher than before expansion $\left(\theta_{0}\right)$ for Lineages I and II, respectively. Similar estimated $\tau$ values ( $\mathrm{Li}, 1977)$ suggested that the population expansion in both lineages may date back to about the same historical period.

\section{Discussion}

Prior to the present study, genetic analyses on the population structure of albacore were carried out using several different approaches such as morphometric comparisons (Yeh et al., 1996), mtDNA RFLP analysis (Chow and Ushiama, 1995), microsatellite analysis (Takagi et al., 2001), blood group and tag-recapture analysis (Arrizabalaga et al., 2004), nuclear G6PD DNA RFLP analysis (Nakadate et al., 2005) and mtDNA sequence analysis (Yeh et al., 1996; Viñas et al., 1999, 2004; Nakadate et al., 2005). Among these studies, different methods have lead to different results. For example, studies on the Pacific albacores using mtDNA ATPase RFLP (Chow and Ushiama, 1995) and microsatellite DNA analyses on four loci (Takagi et al., 2001) have pointed towards opposing conclusions regarding the north and south populations. Moreover, contradictory results were also obtained regarding albacore population structure between the Atlantic Ocean and the Mediterranean Sea (Viñas et al., 1999, 2004; Pujolar et al., 2003; Arrizabalaga et al., 2004; Nakadate et al., 2005). Selection of the most informative analyzing approach is thus essential. In general, among all approaches, PCR sequence analysis was shown to be more effective in predicting population genetics (Buonnacorsi et al., 2001). Regarding the genetic markers for population genetic studies, the HVR-1 region of the mtDNA control region appears to have a mutation rate paralleling that of population evolution of a species (Page and Holmes, 1998). In particular, for animal species such as albacore tuna which has a worldwide geographic distribution, complete sampling is usually extremely difficult. Data sets obtained from 


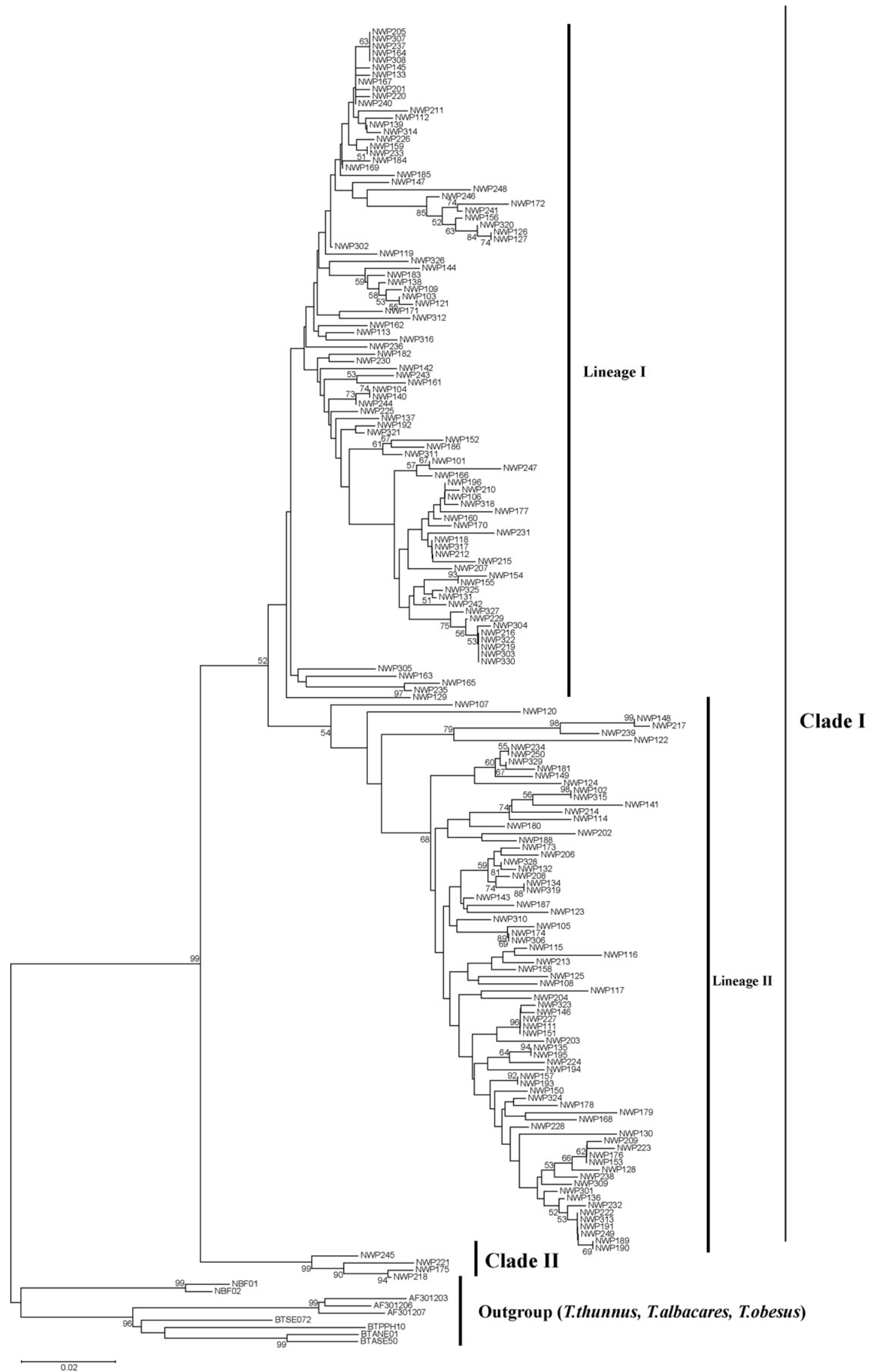

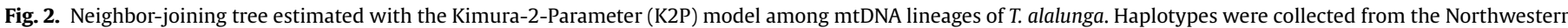
Pacific Ocean (Taiwan, Japan and North of Hawaii). Numbers at nodes indicate the bootstrap values. Only values $>50 \%$ are shown. 
Table 2

Statistical tests of neutrality, and demographic parameters estimates for T. alalunga's entire mitochondrial control region data set, and phylogroups

\begin{tabular}{|c|c|c|c|c|c|}
\hline & All samples & Clade I & Clade I-Lineage I & Clade I-Lineage II & Clade II \\
\hline \multicolumn{6}{|c|}{ Goodness of fit tests } \\
\hline Tajima $D$ & -0.25 & -0.29 & -1.12 & -0.95 & -0.33 \\
\hline Fu's $F_{\mathrm{S}}$ & $-23.75^{*}$ & $-23.77^{*}$ & $-24.28^{*}$ & $-24.27^{*}$ & 0.12 \\
\hline \multicolumn{6}{|c|}{ Demographic parameters } \\
\hline Hri & 0.0007 & 0.0008 & 0.0015 & 0.0024 & 0.4444 \\
\hline SSD & 0.0042 & 0.0071 & 0.0012 & 0.0016 & 0.1975 \\
\hline$S$ & 122 & 127 & 93 & 87 & 15 \\
\hline$\theta_{0}$ & 0.016 & 19.629 & 3.221 & 4.203 & 0.002 \\
\hline$\theta_{1}$ & 45.818 & 461.241 & 62.305 & 196.172 & 4682.500 \\
\hline$\tau$ & 29.674 & 9.024 & 11.773 & 9.554 & 10.438 \\
\hline
\end{tabular}

Hri, Harpending raggedness index (Harpending, 1994); SSD, sum of squared deviations (Schneider and Excoffier, 1999); $\theta$, theta (Rogers, 1995); $\tau$, tau value (Li, 1977).

Significant values at $p<0.05$

DNA sequence analysis can be deposited onto databases such as GenBank and accumulate for later comparisons. Thus, in this study, we investigated phylogenetic relationship and population structure of albacore in the Northwestern Pacific Ocean by sequencing and analyzing the HVR-1 region of the mitochondrial control region.

Samples from all three geographic regions in this study were characterized by high values of haplotype diversity with majority of the haplotypes appearing only once, falling into the typical pattern of Scombroid fishes (Zardoya et al., 2004). This is in concordance with previous albacore data (Chow and Ushiama, 1995; Viñas et al., 1999, 2004; Nakadate et al., 2005). High haplotypic diversity within regional populations can be maintained through large effective population sizes, environmental heterogeneity and life-history traits favoring rapid population increase (Nei, 1987). Nucleotide diversity values of the HVR-1 region were also high, corresponding to those reported for other highly migratory pelagic fishes (Alvarado-Bremer et al., 1997, 2005; Grant and Bowen, 1998; Carlsson et al., 2004; Chiang et al., 2006, 2008). Particularly, high genetic diversities within each regional population for marine fish species such as albacore may be best explained by its characteristics of large population sizes and its wide distribution throughout the world (reviewed in Avise, 1998; Chiang et al., 2006, 2008).

Differentiation among sub-populations of marine fish species is commonly lower than that of freshwater ones. Particularly, it has been shown that genetic differentiation is generally low among tuna populations within and between oceans (Alvarado-Bremer et al., 1998; Grewe and Hampton, 1998; Viñas et al., 1999; Chow et al., 2000; Appleyard et al., 2002; Durand et al., 2005; Chiang et al., $2006,2008)$. The lack of genetic differentiation within an ocean demonstrated extensive gene flow at intra-oceanic scales. In this study, low $F_{\mathrm{ST}}$ values indicated low genetic differentiation between albacore populations from the three Northwestern Pacific regions. Moreover, low and non-significant $\Phi$ statistics $\left(\Phi_{\mathrm{ST}}\right)$ from hierarchical AMOVA also revealed genetic homogeneity among the three regional albacore populations.

In this study, neighbor-joining tree revealed two divergent clades among the three regional albacore populations. Clade I, supported by a weak bootstrap value of $52 \%$ contained $98 \%$ of the total individuals sampled and was further divided into two lineages, lineages I and II, supported by weak bootstrap values of $<50 \%$ and $54 \%$, respectively. Clade II contained $2 \%$ of the total individuals sampled and was supported with a strong bootstrap value of $99 \%$. Previously, two studies on albacore population structure were performed through DNA sequence analysis (Viñas et al., 2004; Nakadate et al., 2005). The two phylogroups revealed in the data of Viñas et al. (2004) seemed to correspond to the two Clade I lineages of this study. Regarding the data of Nakadate et al. (Fig. 4; 2005), two sequences from each of their Clade I (NEA21A/Accession Nos. AB181140, SWA19C/AB181142) and II (MEDL425-6B/AB181141, MED03-33D/AB181143) were deposited onto GenBank. When these four sequences were added to our sequence pool, the reconstructed neighbor-joining tree revealed that sequences of their Clades I and II were grouped, respectively, with Lineages II and I of this study (data not shown). It is interesting to note that one sample was grouped outside of their Clade I and II (Fig. 4, Nakadate et al., 2005). This may correspond to the minor Clade II revealed in the present study. Similar phylogeny pattern of two major mitochondrial control region lineages was also revealed in other closely associated Scombroid fishes such as bigeye tuna (Alvarado-Bremer et al., 1998; Martínez et al., 2005; Chiang et al., 2006, 2008), Atlantic mackerel (Nesbø et al., 2000), swordfish (Alvarado-Bremer et al., 1995, 1996; Rosel and Block, 1996), blue marlin (Finnerty and Block, 1992) and sailfish (Alvarado-Bremer, 1994; Graves and Mcdowell, 1995). In the present study, both lineages of Clade I contained haplotypes from all three sampling regions and no apparent differences were observed in frequencies of these two lineages between the three regional populations. The same condition was observed regarding Clade II, with no presence of haplotypes from North of Hawaii, which may be simply due to the small sample size. In conclusion, it seemed likely that the Northwestern Pacific albacore population shows no apparent phylogeographic distribution.

In the present study, hierarchical AMOVA revealed low and non-significant $\Phi_{\mathrm{ST}}$ for all combinations, suggesting spatial genetic homogeneity not only among albacore populations from different localities, but also within each of the two lineages of Clade I from all three sampling regions. This observation, consistent with the nonsignificant low pairwise $F_{\mathrm{ST}}$ values, suggested a single stock of albacore in the Northwestern Pacific Ocean, given that the existence of two lineages in Clade I is considered. This further indicated possible gene flow between regions within the Northwestern Pacific Ocean.

It has been proposed that based on different combinations of haplotype diversity $(h)$ and nucleotide diversity $(\pi)$ magnitudes of the mtDNA sequences, marine fishes can be classified into four categories (Grant and Bowen, 1998). In the present study, large values of both $h$ and $\pi$ were observed for the three regional albacore populations from the Northwestern Pacific Ocean (Table 1), which characterizes the fourth category of marine fishes defined by Grant and Bowen (1998). High level of divergence is usually associated with either a long evolutionary history in a large stable population or with secondary contacts between previously differentiated allopatric lineages (Grant and Bowen, 1998). To decide which explanation best describes the above albacore phylogroups, sequence data were tested by Tajima's $D$ statistical test. Negative but non-significant Tajima's $D$ values and significant negative Fu's Fs values were revealed for both lineages of Clade I, suggesting possible population expansion. Regarding Clade II, positive non-significant Fu's Fs value suggested that the Clade II population was under equilibrium. Mismatch distribution analysis displayed a unimodal pattern for each of the two lineages of Clade I, suggesting population expansion after genetic isolation (Fu, 1997; 
Harpending, 1994). Clade II exhibited a discontinuous multimodal pattern, which prevented us to predict its demographic history. This may be caused by the small amount of haplotypes in Clade II. Further investigations revealed that the demographic expansion of Clade I and its respective lineages was dated about 400,000 years ago (data not shown). An alternative explanation is that the isolation of populations occurred at the time of population reduction and was followed by the re-establishment of gene flow, since the recovery of populations was slow for lineage I as indicated by the small difference between the estimations of $\theta_{0}$ and $\theta_{1}$, and much faster for lineage II. For Clade II, population reduction seemed to be drastic and the recovery was very fast.

At present, the main albacore fisheries in the Pacific Ocean are roughly divided into North and South Pacific stocks (Nakamura, 1969; Kume, 1974; Bartoo and Foreman, 1994; Murray, 1994; Uosaki and Bayliff, 1999) and managed as distinct units by different associations. In the present study, the demonstration of a panmictic albacore stock throughout the Northwestern Pacific Ocean was supported through the observations of no significant genetic structuring, no apparent phylogeographic distribution, and points to homogeneity within this region. Thus, the continuation of the current management strategy within the Northwestern Pacific is recommended.

\section{Acknowledgments}

We would like to thank Dr. Chaolun Allen Chen and Mr. MingChe Yang for their helpful comments. The funding for this work is provided by National Science Council, Taiwan, ROC (Grant numbers: NSC 92-2313-B-002-060, NSC 95-2611-M-002-013 and NSC 96-2611-M-002-008).

\section{References}

Alvarado-Bremer, J.R., 1994. Assessment of morphological and genetic variation of the swordfish (Xiphias gladius Linnaeus): evolutionary pattern of nucleotide substitution in the mitochondrial genome. Ph.D. Thesis. University of Toronto, Ontario, Canada.

Alvarado-Bremer, J.R., Mejuto, J., Baker, A.J., 1995. Mitochondrial DNA control region sequences indicate extensive mixing of swordfish (Xiphias gladius) populations in the Atlantic Ocean. Can. J. Fish. Aquat. Sci. 52, 1720-1732.

Alvarado-Bremer, J.R., Mejuto, J., Greig, T.W., Ely, B., 1996. Global population structure of the swordfish (Xiphias gladius L.) as revealed by analysis of the mitochondrial DNA control region. J. Exp. Mar. Biol. Ecol. 197, 295-310.

Alvarado-Bremer, J.R., Naseri, I., Ely, B., 1997. Orthodox and unorthodox phylogenetic relationships among tunas revealed by the nucleotide sequence analysis of the mitochondrial DNA control region. J. Fish Biol. 50, 540-554.

Alvarado-Bremer, J.R., Stequert, B., Robertson, N.W., Ely, B., 1998. Genetic evidence for inter-oceanic subdivision of bigeye tuna (Thunnus obesus) populations. Mar. Biol. 132, 547-557.

Alvarado-Bremer, J.R., Viñas, J., Mejutoc, J., Ely, B., Pla, C., 2005. Comparative phylogeography of Atlantic bluefin tuna and swordfish: the combined effects of vicariance, secondary contact, introgression, and population expansion on the regional phylogenies of two highly migratory pelagic fishes. Mol. Phyl. Evol. 36, 169-187.

Appleyard, S.A., Ward, R.D., Grewe, P.M., 2002. Genetic stock structure of bigeye tuna in the Indian Ocean using mitochondrial DNA and microsatellites. J. Fish Biol. 60, 767-770.

Arrizabalaga, H., Costas, E., Juste, J., González-Garcés, A., Nieto, B., LópezRodas, V., 2004. Population structure of albacore Thunnus alalunga inferred from blood groups and tag-recapture analyses. Mar. Ecol. Prog. Ser. 282, 245-252.

Avise, J., 1998. Phylogeography. Harvard University Press, Cambridge, MA.

Bard, F., 2001. Extension of geographical and vertical habitat of albacore (Thunnus alalunga) in the North Atlantic. possible consequences on true rate of exploitation of this stock. ICCAT 52/4, 1447-1456.

Bartoo, N., Foreman, T.J., 1994. A review of the biology and fisheries for North Pacific albacore (Thunnus alalunga). FAO Fish. Tech. Pap. 336, 173-187.

Brown, G.G., Gadaleta, G., Pepe, G., Saccone, C., Sbisa, E., 1986. Structural conservation and variation in the D-loop containing region of vertebrate mitochondrial DNA. J. Mol. Biol. 192, 503-511.

Buonnacorsi, V.P., McDowell, J.R., Graves, J.E., 2001. Reconciling patterns of interocean molecular variance from four classes of molecular markers in blue marlin (Makaira nigricans). Mol. Ecol. 10, 1179-1196.
Carlsson, J., McDowell, J.R., Diaz-Jaimes, P., Carlsson, J.E., Boles, S.B., Gold, J.R., Graves, J.E., 2004. Microsatellite and mitochondrial DNA analyses of Atlantic bluefin tuna (Thunnus thynnus thynnus) population structure in the Mediterranean Sea. Mol Ecol. 13, 3345-3356.

Chiang, H.C., Hsu, C.C., Lin, H.D., Ma, G.C., Chiang, T.Y., Yang, H.Y., 2006. Population structure of bigeye tuna (Thunnus obesus) in the South China Sea, Philippine Sea and western Pacific Ocean inferred from mitochondrial DNA. Fish. Res. 79, 219-225.

Chiang, H.C., Hsu, C.C., Wu, Georgiana, C.C., Chang, S.K., Yang, H.Y., 2008. Population structure of bigeye tuna (Thunnus obesus) in the Indian Ocean inferred from mitochondrial DNA. Fish. Res. 90, 305-1312.

Chow, S., Ushiama, H., 1995. Global population structure of albacore (Thunnus alalunga) inferred by RFLP analysis of the mitochondrial ATPase gene. Mar. Biol. 123, 39-45.

Chow, S., Okamoto, H., Miyabe, N., Hiramatsu, K., Barut, N., 2000. Genetic divergence between Atlantic and Indo-Pacific stocks of bigeye tuna (Thunnus obesus) and admixture around South Africa. Mol. Ecol. 9, 221-227.

Collette, B., Nauen, C., 1983. Scombrids of the world-An annotated and illustrated catalogue of tunas, mackerels, bonitos and related species known to date. FAO Sp. Cat. 2, 137.

Durand, J.D., Collet, A., Chow, S., Guinand, B., Borsa, P., 2005. Nuclear and mitochondrial DNA markers indicate unidirectional gene flow of Indo-Pacific to Atlantic bigeye tuna (Thunnus obesus) populations, and their admixture off southern Africa. Mar. Biol. 147, 313-322.

Excoffier, L., Smouse, P.E., Quattro, J.M., 1992. Analysis of molecular variance inferred from metric distances among DNA haplotypes: application to human mitochondrial DNA restriction data. Genetics 131, 479-491.

Felsenstein, J., 1985. Confidence limits on phylogenies: an approach using bootstrap. Evolution 39, 783-791.

Finnerty, J.R., Block, B.A., 1992. Direct sequencing of mitochondrial DNA detects highly divergent haplotypes in blue marlin (Makaira nigricans). Mol. Mar. Biol. Biotechnol. 1, 206-214.

Fu, Y.X., 1997. Statistical tests of neutrality of mutations against population growth hitchhiking and background selection. Genetics 147, 915-925.

Grant, W.S., Bowen, B.W., 1998. Population histories in deep evolutionary lineages of marine fishes: insights from sardines and anchovies and lessons for conservation. J. Hered. 89, 415-426.

Graves, J.E., Mcdowell, J.R., 1995. Inter-ocean genetic-divergence of istiophorid billfishes. Mar. Biol. 122, 193-203.

Grewe, P., Hampton, J., 1998. An assessment of bigeye (Thunnus obesus) population structure in the Pacific Ocean, based on mitochondrial DNA and DNA microsatellite analysis. SPEST Publication 98-05, JIMAR Contribution 98-320.

Guo, S., Thompson, E., 1992. Performing the exact test of Hardy-Weinberg proportion for multiple alleles. Biometrics 48, 361-372.

Hall, T.A., 1999. BioEdit: a user-friendly biological sequence alignment editor and analysis program for Windows 95/98/NT. Nucleic Acids Symp. Ser. 41, 95-98.

Harpending, R.C., 1994. Signature of ancient population growth in a low-resolution mitochondrial DNA mismatch distribution. Hum. Biol. 66, 591-600.

Kimura, M., 1980. A simple method for estimating evolutionary rate of base substitutions through comparative studies of nucleotide sequences. J. Mol. Evol. 16 $111-120$.

Kumar, S., Tamura, K., Nei, M., 2004. MEGA3: Integrated software for molecular evolutionary genetics analysis and sequence alignment. Brief. Bioinform. 5, 150-163.

Kume, S., 1974. Tuna fisheries and their resources in the Pacific Ocean. Indo-Pac. Fish. Coun. Proc. 15, 390-423.

Li, W.H., 1977. Distribution of nucleotide differences between two randomly chosen cistron in a finite population. Genetics 85, 331-337.

Lynch, M., Crease, T.J., 1990. The analysis of population survey data on DNA sequence variation. Mol. Biol. Evol. 7, 337-394.

Mantel, N., 1967. The detection of disease clustering and a generalized regression approach. Cancer Res. 27, 209-220.

Martínez, P., González, E.G., Castilho, R., 2005. Genetic diversity and historical demography of Atlantic bigeye tuna (Thunnus obesus). Mol. Phylogenet. Evol. 39, 404-416.

Murray, T., 1994. A review of the biology and fisheries for albacore, Thunnus alalunga in the South Pacific Ocean. FAO Fish. Tech. Pap. 336, 188-206.

Nakadate, M., Viñas, J., Corriero, A., Clarke, S., Suzuki, N., Chow, S., 2005. Genetic isolation between Atlantic and Mediterranean albacore populations inferred from mitochondrial and nuclear DNA markers. J. Fish Biol. 66, 1545-1557, doi:10.1111/j.1095-8649.2005.00705.x.

Nakamura, H., 1969. Tuna Distribution and Migration. Fishing News (Books) Ltd., London, 76pp.

Nei, M., 1987. Molecular Evolutionary Genetics. Columbia University Press, New York.

Nesbø, C.L., Rueness, E.K., Iversen, S.A., Skagen, D.W., Jakobsen, K.S., 2000. Phylogeography and population history of Atlantic mackerel (Scomber scombrus L.): a genealogical approach reveals genetic structuring among the eastern Atlantic stocks. Proc. R. Soc. Lond., B 267, 281-292.

Page, Roderic D.M., Holmes, Edward C., 1998. Molecular Evolution-A Phylogenetic Approach. Blackwell Science Ltd.

Pujolar, J.M., Roldán, M.I., Pla, C., 2003. Genetic analysis of tuna populations Thunnus thynnus thynnus and T. alalunga. Mar. Biol. 143, 613-621. 
Ramos-Onsins, S.E., Rozas, J., 2002. Statistical properties of new neutrality tests against population growth. Mol. Biol. Evol. 19, 2092-2100.

Rogers, A., 1995. Genetic evidence for a Pleistocene population explosion. Evolution 49, 608-615.

Rosel, P.E., Block, B.A., 1996. Mitochondrial control region variability and global population structure in the swordfish, Xiphias gladius. Mar. Biol. 125, 11-22.

Rozas, J., Sanchez-Del Barrio, J.C., Messeguer, X., Rozas, R., 2003. DnaSP, DNA polymorphism analyses by the coalescent and other methods. Bioinformatics 19, 2496-2497.

Saccone, C., Attimonelli, M., Sbisa, E., 1987. Structural elements highly preserved during the evolution of the $\mathrm{D}$-loop containing region in vertebrate mitochondria DNA. J. Mol. Evol. 26, 205-211.

Saitou, N., Nei, M., 1987. The neighbor-joining method: a new method for reconstructing phylogenetic tree. Mol. Biol. Evol. 4, 406-425.

Schneider, S., Excoffier, L., 1999. Estimation of past demographic parameters from the distribution of pairwise differences when the mutation rates vary among sites: application to human mitochondrial DNA. Genetics 152, 1079-1089.

Schneider, S., Roessli, D., Excoffier, L., 2000. ARLEQUIN, Version 2.000: A Software for Population Genetics Data Analysis. University of Geneva, Switzerland.

Smouse, P.E., Long, J.C., Sokal, R.R., 1986. Multiple regression and correlation extensions of the Mantel Test of matrix correspondence. Syst. Zool. 35, 627-632.

Tajima, F., 1983. Evolutionary relationship of DNA sequences in finite populations. Genetics 105, 437-460.

Tajima, F., 1989a. The effect of change in population size on DNA polymorphism. Genetics 123, 597-601.

Tajima, F., 1989b. Statistical methods for testing the neutral mutation hypothesis by DNA polymorphism. Genetics $123,585-595$.
Takagi, M., Okamura, T., Chow, S., Taniguchi, N., 2001. Preliminary study of albacore (Thunnus alalunga) stock differentiation inferred from microsatellite DNA analysis. Fish. Bull. US 99, 697-701.

Thompson, J.D., Gibson, T.J., Plewniak, F., Jeanmougin, F., Higgins, D.G., 1997. The CLUSTALX windows interface: flexible strategies for multiple sequence alignment aided by quality analysis tools. Nucleic Acids Res. 25, 4876-4882.

Uosaki, K., Bayliff, W.H., 1999. A review of the Japanese longline fishery for tunas and billfishes in the eastern Pacific Ocean, 1988-1992. Inter-Amer. Trop. Tuna Comm. Bull. 21, 273-488.

Uozumi, Y., 2004. “Thunnus alalunga” (On-line). 2004 IUCN Red List of Threatened Species. Accessed December 16, 2005 at http://www.redlist.org/.

Viñas, J., Santiago, J., Pla, C., 1999. Genetic characterization and AtlanticMediterranean stock structure of albacore, Thunnus alalunga. ICCAT Collect. Vol. Sci. Pap. 49, 188-191.

Viñas, J., Alvarado Bremer, J.R., Pla, C., 2004. Inter-oceanic genetic differentiation among albacore (Thunnus alalunga) populations. Mar. Biol. 145, 225-232.

Watterson, G., 1975. On the number of segregating sites in genetical models without recombination. Theor. Popul. Biol. 7, 256-276.

Wright, S., 1951. The genetical structure of population. Ann. Eugen. 15, 323-354.

Wright, S., 1965. The interpretation of population structure by F-statistics with special regard to systems of mating. Evolution 19, 395-420.

Yeh, S.Y., Hui, C.F., Tseng, T.D., Kuo, C.L., 1996. Indian Ocean albacore stock structure studies by morphometric and DNA sequence methods. IPTP Collect. 9, 258-263.

Zardoya, R., Castilho, R., Grande, C., Favre-Krey, L., Caetano, S., Marcato, S., Krey, G., Patarnello, T., 2004. Differential population structuring of two closely related fish species, the mackerel (Scomber scombrus) and the chub mackerel (Scomber japonicus), in the Mediterranean Sea. Mol. Ecol. 13, 1785-1798. 